\title{
Investigation on the Chemical Reactivity of 2,4-Diamino-6- vinyl-s-triazine with Epoxide
}

\author{
Kazuo KamagatA, Masashi KinoshitA, and Shuuji YoshidA \\ Research \& Development Center, Shikoku Chemicals Corp. \\ 25-1 Miyako, Namegawa, Hiki-gun, Saitama 355, Japan
}

(Received May 21, 1985)

\begin{abstract}
Simultaneously interpenetrating polymer network based on 2,4-diamino-6-vinyl$s$-triazine (VT)/diglycidyl ether of bis-phenol A(DGEBA) was studied using differential thermal analysis and infrared spectroscopy. VT is a candidate of a monomer which increases the glass transition temperature and toughness of an epoxide resin simutaneously. The reactivity of amino groups of VT is considerably higher than 2,4-diamino-6-ethyl-s-triazine (ET) or melamine. Some of the amino groups of VT react with epoxide resin along with the polymerization of epoxide by imidazole. The polymerization of epoxide by imidazole is enhanced presumably by the catalyst effect of VT. The polymerization of double bonds is a fairly low unless peroxide is added at $150^{\circ} \mathrm{C}$. Suitable molar ratio of peroxide and imidazole and the excess amounts of both compounds are required to complete both reactions simultaneously.
\end{abstract}

KEY WORDS 2,4-Diamino-6-vinyl-s-triazine / 2,4-Diamino-6-ethyl-striazine / Melamine / Epoxide Resin / Imidazole / Interpenetrating Polymer Network / DTA / IR / Gel Time /

The mechanical properties of polymers are modified by an interpenetrating polymer network (IPN). The synthesis, morphogy, and physical properties of IPN have been described by many authors. ${ }^{1-5}$ IPN is defined as a combination of two polymers in a network form, with the restriction that at least one of the polymers is synthesized and/or crosslinked in the immediate presence of the other. ${ }^{4}$ IPN is prepared by some methods such as sequential or simultaneous synthesis. In sequential synthesis, a performed cross-linked polymer is prepared with a monomer which is then polymerized to form another cross-linked polymer with in the original network.

On the other hand, monomers or linear prepolymers are comined with their respectively cross-linking agents in simultaneous polymerization, followed by simultaneous polymerization and cross-linking of both phase. Kadota et $a .^{6}$ studied simultaneous interpenetrating polymer networks (SIN) prepared by the polymerization of methacrylic acid modified epoxide resin. They prepared SIN possessing some chemical bonds between each network to increase the compatibility. Epoxide and carbonyl groups of methacrylic acid were prepared, followed by the simultaneous homopolymerization of unreacted epoxides and double bonds of the modified epoxide resin using phthalic anhydride and dicumyl peroxide, respectively. In a previous paper, ${ }^{7}$ we reported the physical properties of a simultaneously cured compound of 2,4-diamino-6vinyl-s-triazine (VT) and epoxide resin. The glass transition temperature $\left(T_{\mathrm{g}}\right)$ and the flexual strength of the simultaneously cured compound were superior to those of the cured epoxide resin polymerized with imidazole.

In this paper, we describe the chemical reactivity of VT as a possible monomer which increases $T_{\mathrm{g}}$ and enhances the toughness of ep- 
oxide resin simultaneously by forming SIN in epoxide networks. The interesting point of VT is the reactivity of amino groups of $s$-triazine with epoxides. Therefore, VT may possess two functions as a monomer for a IPN and a curing agent for a epoxide resin simultaneously. Overberger et al. synthesized VT by the reaction of acryl chloride with biguanide sulfate for the first time in $1958 . .^{8}$ Some other ways of synthesis were reported later. ${ }^{9-12}$ Recently, we established the new method of synthesis of VT, where VT is synthesized from 2;4-diamino-6-(2'-methylimidazolyl-(1'))ethyl-s-triazine. ${ }^{13}$

\section{EXPERIMENTAL}

\section{Materials}

Synthesis of VT. The mixture of 2,4-diamino-6-(2'-methylimidazolyl-( $\left.\left.1^{\prime}\right)\right)$ ethyl- $s$ triazine(2MA) and a quartz powder in the presence of sodium sulfide as polymerization inhibitor was heated at $250^{\circ} \mathrm{C}$ for $5 \mathrm{~h}$ under vacuum of $3 \mathrm{~mm} \mathrm{Hg}$. After being cooled, the sublimated product on the wall of the vessel was extracted with water, which gave a residue by filtration. The residue gave VT by recrystallization with water. The yield was close to $70 \%$ of the theoritical amount. The reaction can be written as follows;

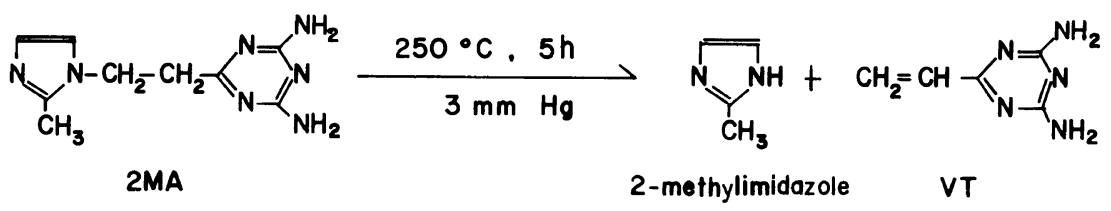

VT obtained was examined using ${ }^{1} \mathrm{H}$ NMR, mass spectroscopy, and high performance liquid chromatography.

This compound had: ${ }^{1} \mathrm{H}$ NMR (DMSO- $\left.d_{6}\right)$ : $\delta 6.76$ (broad singlet, $4 \mathrm{H}$ ), $6.35-6.45$ (triplet, $2 \mathrm{H}$ ), 5.59-5.72 ppm (quartet, $1 \mathrm{H}$ ), IR (potassium bromide): $v 3338,3180,1653,1640,1537$, 1456, 1424, 1363, 1263, 986, $835 \mathrm{~cm}^{-1}$.

Anal. Found: C, $44.28 \% ; \mathrm{H}, 5.09 \%$; $50.52 \%$. Calcd for $\mathrm{C}_{5} \mathrm{H}_{7} \mathrm{~N}_{5}: \mathrm{C}, 43.80 \% ; \mathrm{H}$, $5.11 \%$; N, $51.09 \%$.

Synthesis of ET. As the reference of VT, 2,4- diamino-6-ethyl-s-triazine (ET) was synthesized by propionitrile and dicyandiamide. ${ }^{14}$ The product was obtained in $84 \%$ yield, $\mathrm{mp}$ $250^{\circ} \mathrm{C}$. High performance liquid chromatography indicated $99.4 \%$ purity.

Melamine was used as pure grade reagent. Pure diglycidyl ether of bisphenol A (DGEBA) (mip $46^{\circ} \mathrm{C}$ ) was kindly supplied from Yuka Shell Epoxy Co. and used for the experiments. The structural formula of DGEBA is as follow:

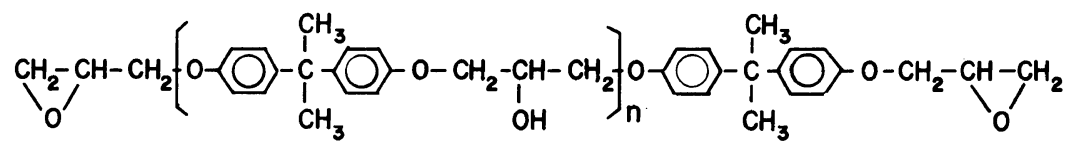

where the content of $n=0$ is $99.7 \%$.

As initiators for VT, dicumyl peroxide (DCP) and $t$-butyl perbenzoate (BPB) were kindly supplied from Nippon Oil and Fats Co.

As the curing agent for DGEBA, 2MA was used. 2MA is a popular curing agent for epoxide resin. ${ }^{15}$

\section{Apparatus and Procedure}

An infrared spectrophotometer (Hitachi 260-10) was used. A sample was placed between $\mathrm{NaCl}$ plates to form a liquid film and 
spectra were obtained in the transmission mode. The $\mathrm{NaCl}$ plates with samples were kept in a conventional oven for a certain period of time, followed by the observation of the spectral change by infrared. Then, it was placed in the oven again for further heating. The quantitative study was carried out by calculating the band height in absorbance mode from transmission spectra of IR. The band assigment was carried out considering band assignment of melamine ${ }^{16}$ and some bands of VT by Oikawa and Kawahara ${ }^{17}$ as references. The amino groups show the vibration in the 3400-3000$\mathrm{cm}^{-1}$ and $1770-1600 \mathrm{~cm}^{-1}$ regions. The spectral change in these regions is a good indicater to observe the extent of the reaction between $\mathrm{NH}$ groups and epoxides. Likewise, the $\mathrm{CH}$ wagging band of the olefine at $962 \mathrm{~cm}^{-1}$ was used to show the extent of the reaction of the double bonds. A Shimadzu thermal analyzer DT-20B was used for the differential thermal analysis (DTA). The chemical reaction between DGEBA and three compounds (VT, ET, and melamine) were studied using DTA. The sample was prepared by mixing $10.0 \mathrm{~g}$ of DGEBA and $2.0 \mathrm{~g}$ of each compound extensived. When one mol of amino group is considered to react with two mol of epoxide, $10.0 \mathrm{~g}$ of DGEBA and $2.0 \mathrm{~g}$ of VT is the stoichiometry. $20 \mathrm{mg}$ of the mixture of DGEBA and each compound were measured as the samples. As a reference, $10 \mathrm{mg}$ of $\mathrm{Al}_{2} \mathrm{O}_{3}$ were used. The heating speed was $5^{\circ} \mathrm{C} \mathrm{min}^{-1}$ and $100 \mu \mathrm{V}$ range was used for the experiment. The temperature was raised from room temperature to $300^{\circ} \mathrm{C}$.

The gel time of the mixture of these three compounds and DGEBA were measured by the stroke curing method on a hot plate at $150^{\circ} \mathrm{C}$ following JIC C2104. The mixture was initially prepared by a slight heating of DGEBA to melt and $20 \mathrm{wt} \%$ of each compound was added. Then, they were mixture at room temperature and repeated mixing. A certain amount of $2 \mathrm{MA}$ was added and mixed well again.

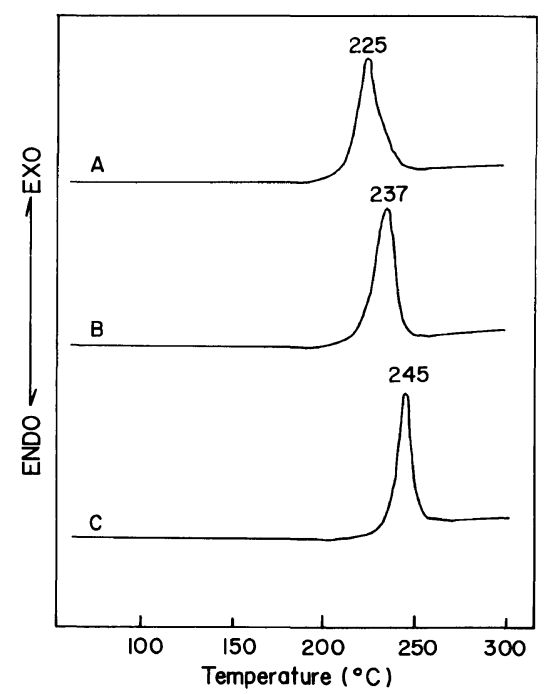

Figure 1. DTA spectra of the mixture of $10.0 \mathrm{~g}$ of DGEBA and $2.0 \mathrm{~g}$ of (A) VT, (B) ET, and (C) melamine. DGEBA, diglycidyl ether of bisphenol A; VT, 2,4diamino-6-vinyl-s-triazine; ET, 2,4-diamino-6-ethyl-striazine.

\section{RESULTS AND DISCUSSION}

\section{Chemical Reactivity of $V T$ with Epoxide}

The DTA spectra of the mixture of DGEBA and VT, ET, and melamine are shown as Figures $1 \mathrm{~A}, 1 \mathrm{~B}$, and $1 \mathrm{C}$, respectively. The mixture of DGEBA and VT (Figure 1A) showed an exothermal peak due to the chemical reaction between VT and DGEBA at $225^{\circ} \mathrm{C}$. On the other hand, the mixture of DGEBA and ET and melamine showed exothermic peaks at 237 and $245^{\circ} \mathrm{C}$, respectively, (Figure $1 \mathrm{~B}$ and Figure 1C). These results indicate the differences in chemical reactivities of VT, ET, and melamine with DGEBA. The differences are probably due to the different $\pi$ electron densities of the compounds. The electron donating property of the substituents increased in the order of $\mathrm{CH}_{2}$ $=\mathrm{CH}>\mathrm{C}_{2} \mathrm{H}_{5}>\mathrm{NH}_{2}$, which corresponds to the order of reaction temperature (peak position) of DGEBA and three compounds. The differences in reactivities among melamine, ET, and VT are possibly due to the differences in the reactivities of amino groups with ep- 


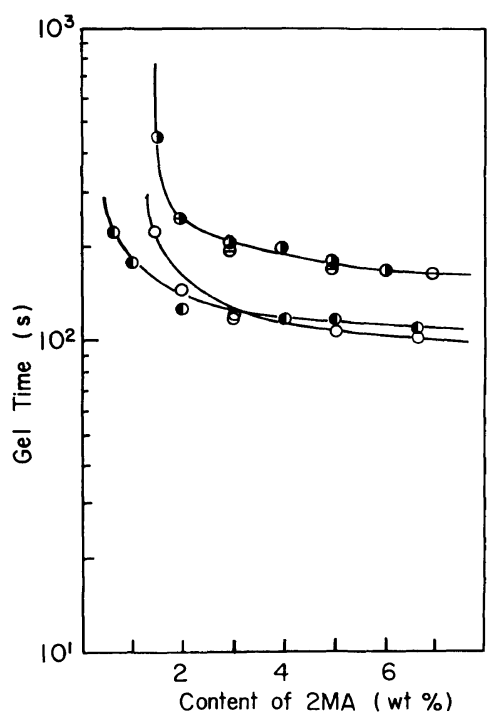

Figure 2. Relationship between gel time and amount of $2 \mathrm{MA}$ to the mixture of $100 \mathrm{~g}$ of DGEBA and $20 \mathrm{~g}$ of VT (O), ET ( $\bigcirc)$, and melamine $(\ominus)$. ( () indicates the only $100 \mathrm{~g}$ of DGEBA as reference. 2MA, 2,4-diamino6-(2'-methylimidazolyl-( $\left.\left(1^{\prime}\right)\right)$ ethyl-s-triazine.

oxide resin. Higher $\pi$ electron density of $s$ triazine provide higher chemical reactivity of amino groups with epoxide. The chemical reaction between melamine and epoxide resin has not been studied extensively because of the low chemical reactivity.

\section{Additional Effects of Imidazole Compound}

The chemical reaction between DGEBA and VT was further studied by observation of gel time and IR spectra. The relationship between gel time and the amount of 2MA added is shown in Figure 2. The gel time curve of DGEBA/melamine mixture did not show a major difference from the reference mixture of DGEBA and 2MA, indicating no accelation of the gel time by melamine. On the other hand, DGEBA/VT and ET mixtures showed remarkable shortening of gel time by the addition of the 2MA compound to the reference mixture. The DGEBA/VT mixture especially indicates the rapid decrease in gel time by the addition of a slight amount of 2MA. The chemical reaction of the DGEBA/VT mixture

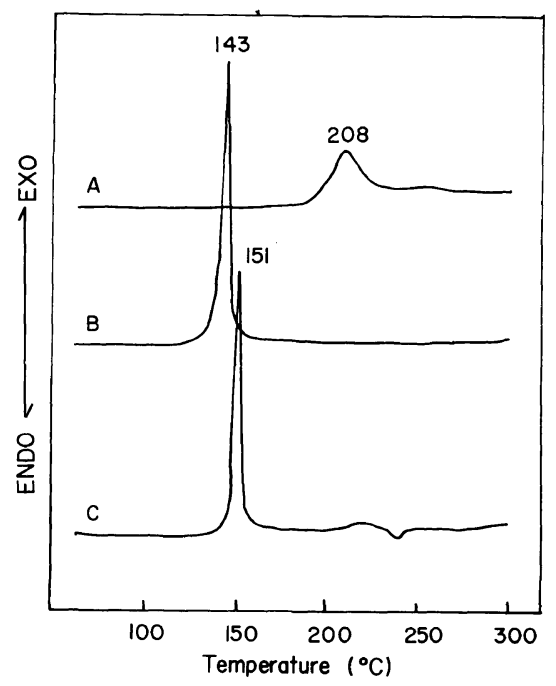

Figure 3. DTA spectra of the mixture of DGEBA/VT/2MA possessing the following composition $(\mathrm{wt} \%$ ): (A) $83.3 / 16.5 / 0.2 ; \quad$ (B) $83.3 / 9.0 / 7.7 ; \quad$ (C) 83.3/0/16.7.

by the addition of $2 \mathrm{MA}$ was further studied using DTA. Figures $3 \mathrm{~A}, \mathrm{~B}$, and $\mathrm{C}$ indicated DTA spectra of mixtures of DGEBA/VT/2MA with the composition of $83.3 / 16.5 / 0.2$ $\mathrm{wt}^{\mathrm{o}} \%, 83.3 / 9.0 / 7.7$, and $83.3 / 0 / 16.7$, respectively. Figure $3 \mathrm{~A}$ shows a relatively broad and small exothermic peak at $208^{\circ} \mathrm{C}$ with a shoulder, which is about $17^{\circ} \mathrm{C}$ lower than the mixture without 2MA (Figure 1A). The shifting of the peak to the low temperature is due to the catalystic effect of 2MA added. This effect is cleary seen in Figure $3 \mathrm{~B}$, where the peak position has shifted by $65^{\circ} \mathrm{C}$ to the lower temperature compared to Figure $3 \mathrm{~A}$. In addition, the peak position of Figure $3 \mathrm{~B}$ is higher than Figure $3 \mathrm{C}$ by $8^{\circ} \mathrm{C}$, which means the mixtures of $7.7 \mathrm{wt}^{\mathrm{o}} \%$ of $2 \mathrm{MA}$ and $9.0 \mathrm{wt} \%$ of VT possess higher reactivity with epoxide resin than $16.7 \mathrm{wt} \%$ of $2 \mathrm{MA}$. This indicates that VT was catalyzed by $2 \mathrm{MA}$, resulting in the higher reactivity with epoxide than $2 \mathrm{MA}$ alone. From the infrared spectra of the cured compounds of VT and a commercial epoxide resin (Epikote \#828) in the presence of $2 \mathrm{MA}$ at the peak of DTA thermograms, ${ }^{7}$ it was clear that the 


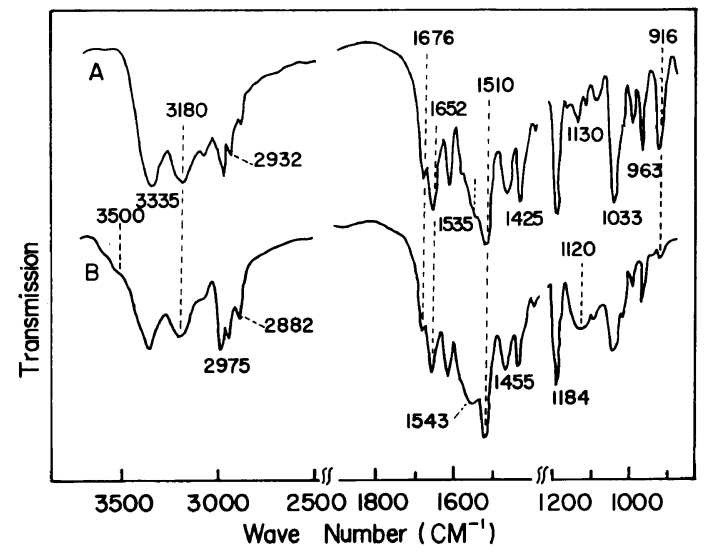

Figure 4. Infrared spectra of the mixture of DGEBA/VT/2MA $(82.7 / 16.5 / 0.8 \mathrm{wt} \%$ ): (A) initial; (B) after heating at $150^{\circ} \mathrm{C}$ for $2.2 \mathrm{~h}$.

absorption of epoxide disappers almost on heating to $150^{\circ} \mathrm{C}$, but the absorption of amino groups did not disappear on heating to $250^{\circ} \mathrm{C}$.

The spectroscopic study of the chemical reaction of VT and DGEBA with a small amount of 2MA was carried out using IR spectroscopy. A good mixture of DGEBA/VT/2MA $(82.7 / 16.5 / 0.8 \mathrm{wt} \%)$ was placed between $\mathrm{NaCl}$ plate to make a thin film. The spectral change was observed after heating for a certain period of time at $150^{\circ} \mathrm{C}$. The initial spectrum of the mixture is shown as Figure 4A. The Figure 4B shows the spectrum heating at $150^{\circ} \mathrm{C}$ for $2.2 \mathrm{~h}$ several spectral changes due to the chemical reactions are observed. The intensity of $\mathrm{NH}_{2}$ stretching bands at $3335 \mathrm{~cm}^{-1}$ and $3180 \mathrm{~cm}^{-1}$ and the bending at $1652 \mathrm{~cm}^{-1}$ were reduced, indicating the chemical reaction between amino groups and epoxides. The broad band around $3500 \mathrm{~cm}^{-1}$ in Figure $4 \mathrm{~B}$ is due to both the polymerization of $\mathrm{VT}$ and $\mathrm{OH}$ groups produced by the chemical reaction between amino groups of VT and epoxide. The chemical reaction between amino groups and epoxides was enhanced by $2 \mathrm{MA}$, because almost no reaction was observed without $2 \mathrm{MA}$ by heating at $150^{\circ} \mathrm{C}$ for this period of time. The new broad band at $1120 \mathrm{~cm}^{-1}$ is due to the stretching band of $\mathrm{O}-\mathrm{C}$ bond and $\mathrm{C}-\mathrm{N}$ bond.

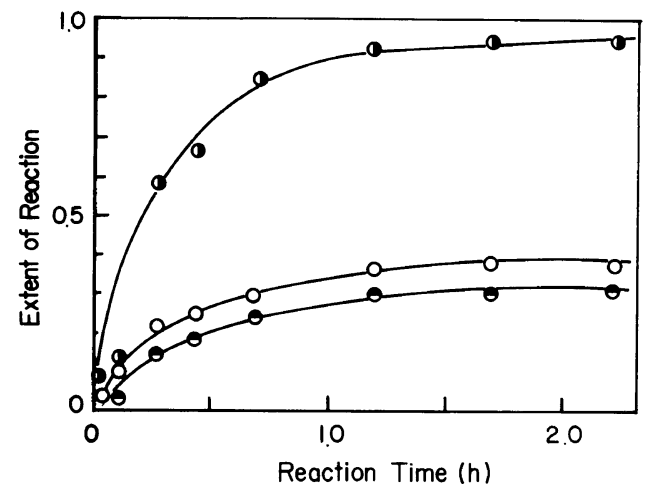

Figure 5. Relationship between reaction time and extent of reaction of epoxide (O), amino group (O), and double bond $(\Theta)$ of the mixture of DGEBA/VT/2MA $\left(82.7 / 16.5 / 0.8 \mathrm{wt}^{\mathrm{o}} \%\right.$ ).

This is a due to the anionic polymerization of epoxides by imidazole and its derivatices ${ }^{18-22}$ and the chemical reaction between epoxides and amines. The extent of the reaction of epoxides was observed by the band at 916 $\mathrm{cm}^{-1}$. Most of the epoxides reacted by heating at $150^{\circ} \mathrm{C}$ for $2.2 \mathrm{~h}$. However, the double bond at $963 \mathrm{~cm}^{-1}$ still remained after heating.

The extent of reaction of amino groups, epoxides, and double bonds were plotted versus reaction time in Figure 5. The extent of reaction was obtained by calculating the absorbance from a transmission spectrum, followed by a comparison of the reduction in absorbance due to the reaction with the initial value. The deviation of the initial value from the curve is due to the method of experiment. It took about $2 \mathrm{~min}$ for the plate to become $150^{\circ} \mathrm{C}$ from temperature in the oven. Therefore, this insufficient heating resulted in the deviation from the curve in the region of the short time heating. The kinetic study of this reaction was not possible for this reason. However, the reaction curve of epoxide does not show the typical sigmoidal curve of Ricciardi ${ }^{21}$ and Kakiuchi ${ }^{22}$ due to imidazole curing, indicating that some other reactions take place at the same time. The reaction curves of both amino groups and double bonds showed similar trends to epoxides, even though the 


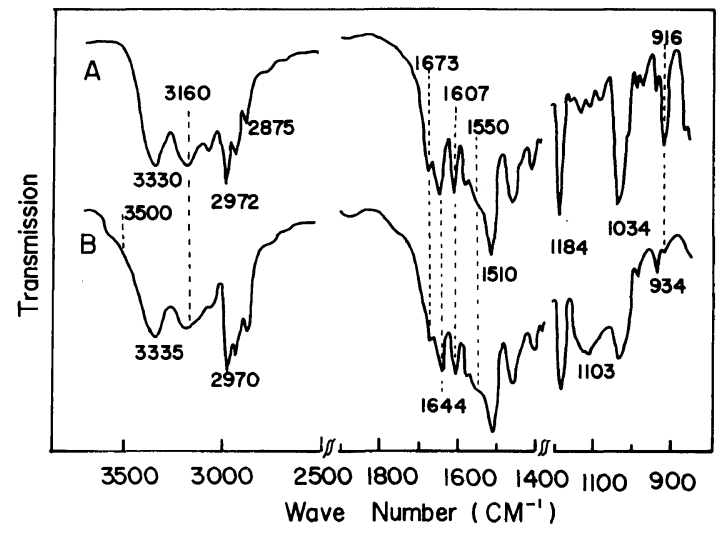

Figure 6. Infrared spectra of the mixture of DGEBA/VT/2MA (82.7/16.5/0.8 wt \%): (A) initial; (B) after heating at $150^{\circ} \mathrm{C}$ for $8.3 \mathrm{~h}$.

reactivities were lower than epoxides. ${ }^{23}$ As the polymerization of epoxides progresses, other reaction speeds become low because of the lowered diffusion. The clevage speed of double bonds is thus much lower than the reaction speed of epoxides. However, heating at higher temperature greatly enhances the reaction speeds of both double bonds and amino groups compared to that of epoxides.

The chemical reaction of DGEBA/ET/2MA $(82.7 / 16.5 / 0.8 \mathrm{wt} \%)$ was studied in the same manner. The spectral changes due to the reactions are shown in Figure 6. The reactions of the amino groups at $1645 \mathrm{~cm}^{-1}$ and epoxide at $916 \mathrm{~cm}^{-1}$ were observed. However, the extent of reactions of amines was less than the VT mixture shown in Figure 4B. The relationship between the extent of reaction and reaction time of amines and epoxides is ploted in Figure 7, where the reaction speeds of epoxides are considerably low compared to Figure 5. The epoxides reacted gradually after $1.5 \mathrm{~h}$, following the rapid initial reaction. About $20 \%$ of the amino groups reacted by heating for $1.5 \mathrm{~h}$ at $150^{\circ} \mathrm{C}$. However, further reaction could not be observed after that.

The clear difference between VT and ET observed in Figure 2 was the different gel time, especially by the addition of less than $2.0 \mathrm{wt} \%$

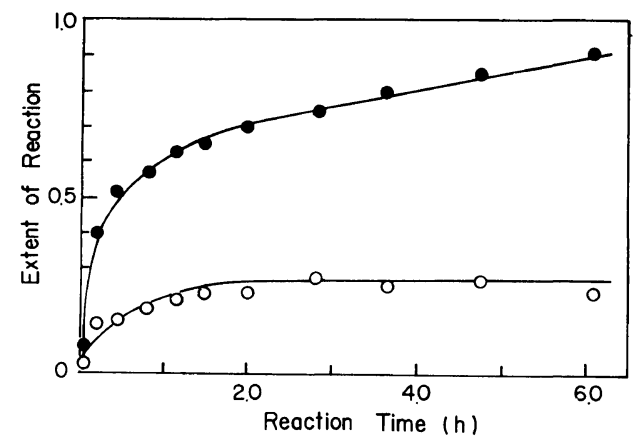

Figure 7. Relationship between reaction time and extent of reaction of epoxide $(O)$ and amino group $(O)$ of the mixture of DGEBA/ET/2MA $(82.7 / 16.5 / 0.8 w t \%)$.

of 2MA to the mixture. This was be due the difference in reactivities of amino groups of each compounds with epoxide resin, and was attributed to the different $\pi$ electron densities of the ring. The chemical reactions between amino groups and epoxides are catalyzed by imidazole. The degree of enhancement of the reactivity by the addition of $2 \mathrm{MA}$ also depends on the $\pi$ electron density of the ring. VT with a higher electron density is catalized more than ET by a slight amount of $2 \mathrm{MA}$ addition. The initial reaction compound of the epoxides and each compound might give catalystic effects for the polymerization of epoxides. However, further study is required to confirm this.

\section{Additional Effects of Peroxides}

It was necessary to cleave double bonds to optimize the mechanical properties of the resin in IPN. However, considerable amounts of double bonds of VT were still observed after most of the epoxides reacted (Figure 4). Therefore, radical initiators such as dicumyl peroxide (DCP) or $t$-butyl peroxybenzoate (BPB) were added to the mixture of DGEBA/ VT/2MA to complete the polymerization of double bonds. The infrared spectra of DGEBA/VT/2MA/DCP $\quad(82.6 / 16.5 / 0.2 / 0.7$ $\mathrm{wt}^{\circ} \%$ ) mixture is shown in Figure $8 \mathrm{~A}$ after heating at $150^{\circ} \mathrm{C}$ for $11.5 \mathrm{~h}$. The spectrum shows the characteristic polymerization of VT 


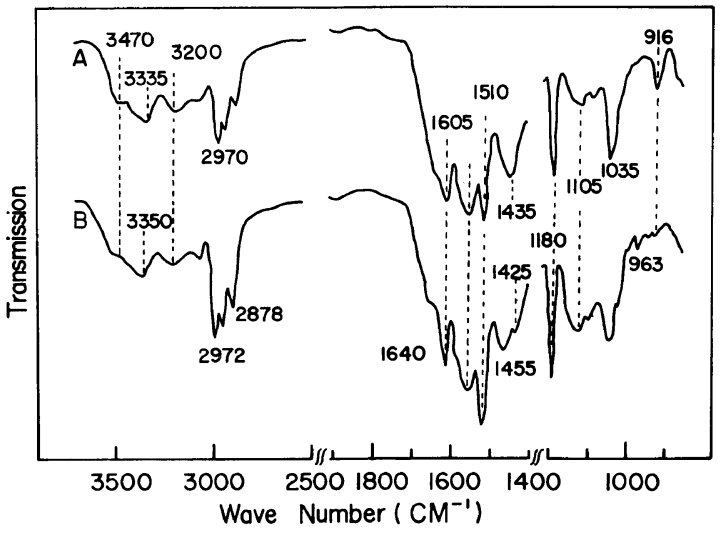

Figure 8. Infrared spectra of the mixture of DGEBA/VT/2MA/DCP of (A) 82.6/16.5/0.2/0.7 after heating for $11.5 \mathrm{~h}$ at $150^{\circ} \mathrm{C}$ and (B) $80.6 / 16.1 / 2.6 / 0.7$ after heating for $3.3 \mathrm{~h}$ at $150^{\circ} \mathrm{C}$. DCP, dicumyl peroxide.

at 3470,3350 , and $3200 \mathrm{~cm}^{-1}$, as observed by the polymerization of VT by peroxides. In addition, the $\mathrm{CH}_{2}$ wagging band of double bonds at $963 \mathrm{~cm}^{-1}$ disappeared almost completely. However, $40 \mathrm{wt} \%$ of the epoxides band at $916 \mathrm{~cm}^{-1}$ still remained after the heating. The mixture of DGEBA/2MA/DCP (80.6/ $16.1 / 2.6 / 0.7 \mathrm{wt} \%$ ) containing more $2 \mathrm{MA}$ was studied to promote the reaction of epoxides. The infrared spectrum of the mixture after heating at $150^{\circ} \mathrm{C}$ for $3.2 \mathrm{~h}$ is shown in Figure $8 \mathrm{~B}$. The increased reaction of epoxide at 916 $\mathrm{cm}^{-1}$ was observed. Nevertheless, $23 \%$ of the double bonds still remained unreacted, which is much more than the mixture containing less 2MA (Figure 8A). This indicates that the increased addition of $2 \mathrm{MA}$ decreases the reaction of double bonds.

The extent of the reaction of the mixture containing different ratios of $2 \mathrm{MA}$ and peroxide are studied further in Figure $9.100 \mathrm{~g}$ of DGEBA were mixed well with $20 \mathrm{~g}$ of VT. Then, a certain amount of $2 \mathrm{MA}$ and peroxide of different ratios were added to the mixture of DGEBA and VT. Finally, these compounds were again mixed well for spectroscopic study. The extent of the reactions of epoxides at $916 \mathrm{~cm}^{-1}$ and double bonds at $962 \mathrm{~cm}^{-1}$ were observed after $20 \mathrm{~min}$ and $1.3 \mathrm{~h}$ from the spec-

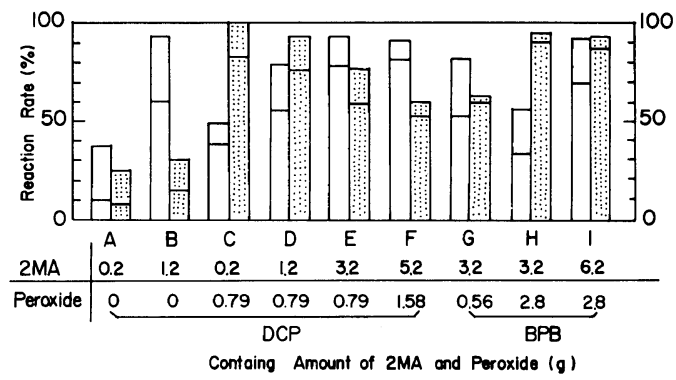

Figure 9. Extent of reaction of epoxide and a double bond at $150^{\circ} \mathrm{C}$ for $20 \mathrm{~min}$ and $1.3 \mathrm{~h}$. Each compound contains $100 \mathrm{~g}$ of DGEBA and $20 \mathrm{~g}$ of VT and the mixture of $2 \mathrm{MA} /$ peroxide. $\square$, epoxide; 圈, double bond; $\square$, after heating at $150^{\circ} \mathrm{C}$ for $20 \mathrm{~min}$; $\boxminus$, after heating at $150^{\circ} \mathrm{C}$ for $1.3 \mathrm{~h}$.

tral change. The mixture containing $0.2 \mathrm{~g}$ and $1.2 \mathrm{~g}$ of $2 \mathrm{MA}$ in the DGEBA and VT mixture are shown in Figure 9A and Figure 9B, respectively, and compared to the mixture containing both $0.2 \mathrm{~g}$ of $2 \mathrm{MA}$ and $0.79 \mathrm{~g}$ of DCP (Figure 9C). By the increase of 2MA, the reaction speed of peroxide obviously increased. However, the extent of the reaction of double bonds did not increase significantly (Figures 9A and 9B). By the addition of DCP the reaction speed of the double bonds increased very much (Figure 9C) compared to the one in Figure 9A.

Mixtures containing different ratios of 2MA/DCP in the presence of DGEBA and VT $(1.2 \mathrm{~g} / 0.79 \mathrm{~g}$, and $5.2 / 1.58)$ are shown in Figures $9 \mathrm{D}, 9 \mathrm{E}$, and $9 \mathrm{~F}$, respectively. It is interesting to compare Figures 9C, 9D, and $9 \mathrm{E}$, because the amounts of DCP were constant, although the amount of $2 \mathrm{MA}$ varied. The extent of the reactions of epoxides increased by increasing 2MA. However, the extent of the reactions of double bonds decreased. The increased addition of both 2MA and DCP did not show remarkable increase in either reaction (Figure 9F).

The more reactive peroxide at considerably low temperature was used to improve the cleavage speed of double bonds (Figures 9G, 9H, and 9I). The decomposition temperature 
of $\mathrm{BPB}$ is $128^{\circ} \mathrm{C}$, which is $12^{\circ} \mathrm{C}$ lower than that of DCP. The extent of the reaction of the mixture containing different ratios of $2 \mathrm{MA} /$ BPB in the DGEBA and VT mixture (3.2/ $0.56 \mathrm{~g}, 3.2 / 2.8$, and 6.2/2.8) is shown in Figures $9 \mathrm{G}, 9 \mathrm{H}$, and $9 \mathrm{I} .0 .79 \mathrm{~g}$ of DCP and $0.56 \mathrm{~g}$ of BPB are equivalent moles. The different extents of reactions between DCP and BPB can be observed by comparing Figures $9 \mathrm{E}$ and $9 \mathrm{G}$, where they contain the same amount of $2 \mathrm{MA}$ and the equivalent mole of another peroxide. The extent ' of the reaction of double bond in Figure $9 \mathrm{G}$ after heating for $20 \mathrm{~min}$ is slightly higher than Figure 9E, even though it did not increase by further heating. However, the extent of the reaction of epoxide by BPB in Figure $9 \mathrm{G}$ is lower than that by DCP in Figure 9E. This probably indicates the faster cleavage reactions of double bonds since BPB results in the depression of reactions of epoxides.

The extent of the reaction of the double bonds increased by increasing BPB (Figure $9 \mathrm{H})$. However, the reaction of epoxide was depressed considerably. This is opposite to the phenomenon where depression of the cleavage of double bonds occurred by increasing $2 \mathrm{MA}$. The extent of reactions of double bonds and epoxides depends on the ratios of peroxide and 2MA. Figure 9I shows the most extended reactions of epoxides and double bonds, which require fairly large amounts of $2 \mathrm{MA}$ and peroxides. The addition of $3.2 \mathrm{~g}$ of $2 \mathrm{MA}$ is enough to cure DGEBA and $0.56 \mathrm{~g}$ of $\mathrm{BPB}$ is also enough to polymerize VT separately. However, Figure 9I indicates that $6.2 \mathrm{~g}$ of 2MA and $2.8 \mathrm{~g}$ of BPB are necessary to complete both reactions simultaneously. These results above indicate the enhancement of reactivity of one group to cause a rapid drop of the diffusion of the system. Therefore, the other reactive groups can not obtain sufficient contacts for the reaction in a limited diffusion condition. Therefore, a suitable ratio of peroxide and 2MA and excess amount of these two compounds are required for the reactions in IPN to proceed.

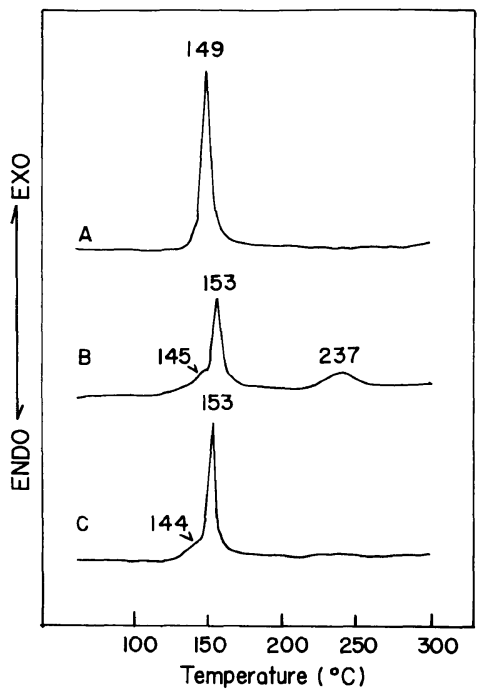

Figure 10. DTA spectra of DGEBA/VT/2MA/BPB mixture containing $100 \mathrm{~g}$ of DGEBA, $20 \mathrm{~g}$ of $\mathrm{VT}$ and $1 \mathrm{MA} / \mathrm{BPB}$ of (A) $3.2 \mathrm{~g} / 0.56 \mathrm{~g}$, (B) $3.2 / 2.8$, and (C) $6.2 / 2.8$.

The DTA study of DGEBA/VT/2MA/BPB mixture was carried out as shown in Figure 10. The DTA spectra of Figures 10A, 10B, and 10C correspond to the same mixture of Figure 9G, 9H, and 9I, respectively. The molar ratio of $2 \mathrm{MA} / \mathrm{BPB}$ of Figures $10 \mathrm{~A}, 10 \mathrm{~B}$, and $10 \mathrm{C}$ are $3.2 \mathrm{~g} / 0.56 \mathrm{~g}, 3.2 / 2.8$, and $6.2 / 2.8$, respectively. The extent of reactions of epoxide/ double bonds of Figures 10A, 10B, and 10C after heating at $150^{\circ} \mathrm{C}$ for $1.3 \mathrm{~h}$ are $82 \% / 63 \%$, $55 / 95$, and $92 / 93$. Figure $10 \mathrm{~A}$ shows the only one exothermic peak, which is probably due to the polymerization of epoxide by $2 \mathrm{MA}$ as well as the polymerization of double bonds by BPB. These two reactions probably occurred at the same temperature. Figures $10 \mathrm{~B}$ and $10 \mathrm{C}$ show the small shoulder peak at $145^{\circ} \mathrm{C}$ besides the main peak at $153^{\circ} \mathrm{C}$. This shoulder peak at $145^{\circ} \mathrm{C}$ is possibly due to the polymerization of VT and the peak at $153^{\circ} \mathrm{C}$ is due to the polymerization of epoxide. The shift of the main peak to higher temperature is probably due to the restricted reaction of epoxides caused by the initial polymerization of double bonds. The broad peak at $237^{\circ} \mathrm{C}$ in Figure $10 \mathrm{~B}$ 
is presumably due to the reaction of unreacted epoxide and poly VT, because most VT was polymerized initially as seen in Figure $9 \mathrm{H}$. The chemical reaction between VT and DGEBA was observed at $225^{\circ} \mathrm{C}$ without $2 \mathrm{MA}$ in Figure 1A. Therefore, the same reaction possibly takes place between amino groups of poly VT and epoxide. In Figure $10 \mathrm{C}$, the broad band at $237^{\circ} \mathrm{C}$ is not cleary observed, because of the progress of the polymerization of epoxide by the increased concentration of $2 \mathrm{MA}$.

\section{CONCLUSION}

Melamine, ET, and VT showed different reactivities with DGEBA, because of the different $\pi$ electron densities of $s$-triazine ring. An ET or VT mixture of DGEBA showed considerable decrease of gel time by the addition of 2MA. However, the melamine and DGEBA mixtures did not show this. This shortening of gel time is due to the catalyzed reactivity of the amino groups of ET and VT by $2 \mathrm{MA}$. Amino groups of VT and ET react with epoxide along with the polymerization of epoxide by the addition of a slight amount of 2MA. The reaction curve of double bonds of VT was similar to those of the amino groups at $150^{\circ} \mathrm{C}$. The reactivities of epoxide and amino groups of ET were lower than VT by the addition of $0.8 \mathrm{wt} \%$ of $2 \mathrm{MA}$ because of the lower $\pi$ electron density of the ring. By the addition of DCP, the polymerization of double bonds increased. However, polymerization of epoxide was suppressed. On the other hand, the excess amount of 2MA caused depression of the polymerization of double bond. This is attributed to the rapid drop of diffusion caused by the progress of the reaction of one group. A suitable molar aatio of peroxide and 2MA and excess amount of these two compounds are necessary to complete two kinds of reactions simultaneously.

Acknowledgement. The authors wish to excess their appreciation to executive director Dr. Natsuo Sawa of Shikoku Chemicals Corp. for their helpful discussion.

\section{REFERENCES}

1. K. Shibata and Y. Suzuki, Kobunshi Kagaku, 23, 24 (1966).

2. K. F. Muller and S. J. Heiber, J. Appl. Polym. Sci., 27, 4043 (1982).

3. K. C. Frisch, D. Klempner, and H. L. Frisch, Polym. Eng., 22, 1143 (1982).

4. J. M. Widmaier and L. H. Sperling, J. Appl. Polym. Sci., 27, 3513 (1982).

5. D. J. Hourston and Y. Zia, J. Appl. Polym. Sci., 28, 2139 (1983).

6. M. Kadota and Y. Suzuki, Kobunshi Ronbunshu, 40, 505 (1983).

7. K. Kamagata, S. Yoshida, and T. Mizui, Kobunshi Ronbunshu, 42, 473 (1985).

8. C. G. Overbergar and F. W. Michellatti, J. Am. Chem. Soc., 80, 988 (1958).

9. Hoechst, France Patent, 1563255 (1967).

10. Asahikasei, Japan Patent, 46-35068.

11. Suddeutsche Kalkstickoff Werke A. G., Germany Patent 2135881 (1973).

12. Y. Yuki, T. Kakurai, and T. Noguchi, Bull. Chem. Soc. Jpn., 43, 2123 (1970).

13. Shikoku Chemicals, submitted to Japan Patent, Tokugansho 59-242652.

14. N. R. Smyrl and R. W. Smithwich, J. Heterocyclic Chem., 19, 493 (1982).

15. Shikoku Chemicals, Technical Report, "Curezol," 1977.

16. N. B Colthup, L. H. Poly, and S. E. Wilberly, "Introduction to Infrared and Raman Spectroscopy," American Press, New York, N. Y., 1975, pp 273-274.

17. E. Oikawa and M. Kawahara, J. Macromol. Sci., A9, 1439 (1975).

18. A. Farkas and P. F. Strom, J. Appl. Polym. Sci., 12, 159 (1968).

19. T. J. Dearlove, J. Appl. Polym. Sci., 14, 1615 (1970).

20. F. Ricciardi, W. A. Romanchick, and A. A. Griscage, J. Polym. Sci., Polym. Lett. Ed., 20, 127 (1982).

21. F. Ricciardi, W. A. Romanchick, and M. M. Joullie, J. Polym. Sci., Polym. Chem. Ed., 21, 1475 (1983).

22. H. Kakiuchi and N. Futatsugi, Preprint, 33th Conference of Thermosetting Plastics, Tokyo, 1984, p 1.

23. K. Kamagata and S. Yoshida, in preparetion.

24. Nippon Oil and Fats, Technical Report, "Organic Peroxide," 1984. 